\title{
Optimization of artificial neural network by genetic algorithm for describing viral production from uniform design data
}

\author{
Maria Beatriz Takahashi*, José Celso Rocha, Eutimio Gustavo Fernández Núñez \\ Departamento de Ciências Biológicas, Universidade Estadual “Júlio de Mesquita Filho” Campus-Assis, Avenida Dom Antonio 2100, Assis, 19806-900 SP, Brazil
}

\section{A R T I C L E I N F O}

\section{Article history:}

Received 12 August 2015

Received in revised form 6 December 2015

Accepted 11 December 2015

Available online 17 December 2015

\section{Keywords:}

Artificial neural network

Bioprocess

Genetic algorithm

Uniform design

Virus production

\begin{abstract}
A B S T R A C T
This work objective was to define a modeling approach based on genetic algorithm (GA) for optimizing parameters of an artificial neural network (ANN); the latter describes rabies virus production in BHK-21 cells based on empirical data derived from uniform designs (UDs) with different numbers of experimental runs. The parameters considered for viral infection were temperature $\left(34\right.$ and $\left.37^{\circ} \mathrm{C}\right)$, multiplicity of infection $(0.04,0.07$, and 0.1$)$, infection, and harvest times $(24,48$, and $72 \mathrm{~h})$, with virus production as the monitored output variable. A multilevel factorial experimental design was performed and used to train, validate, and test the ANN. Its experimental fractions (18, 24, 30, 36, and 42 runs) defined by UDs were used to simulate the neural architectures. In GA, the neural computing parameters constituted the population individuals, and the steps involved were population creation, selection, and replacement by crossover and mutation. The ANN optimized by the combined algorithm showed a good calibration for all UDs under consideration, thus demonstrating to be suitable $(R>0.85)$ as a correlation method in UDs independent of the experimental runs developed. Therefore, this work could guide researchers in the efficient use of UDs in the simulation and optimization of virus production processes.
\end{abstract}

(c) 2015 Elsevier Ltd. All rights reserved.

\section{Introduction}

Animal cell cultures have been used for the production of rabies vaccines since the 1960s due to the neurological deleterious effects caused by first-generation vaccine based on the application of animal nervous tissue [1]. According to World Health Organization (WHO), these vaccines contain an inactivated virus and can be developed in various cell substrates such as human diploid cells, primary chicken embryo cells, Vero cells, or in primary Syrian hamster kidney cells. Recently, the establishment of serum/animal protein free culture media in animal cell cultures at a large scale has improved the safety of rabies viral vaccines and their applications showed efficacy and decrease in production costs $[2,3]$.

In 2004, the Food and Drug Administration (FDA) launched the Quality by design (QbD) and Process analytical technology (PAT) to understand, control, and guarantee quality of pharmaceutical products and the corresponding processes [4]. Since then, the monitoring and design of biopharmaceutical process have improved. The QbD approach is based on four cornerstones: risk-assessment techniques; PAT tools for in-process monitoring and multivariate

\footnotetext{
* Corresponding author.

E-mail address: mbeatriz.takahashi@gmail.com (M.B. Takahashi).
}

controlling; mathematical and statistical tools including design of experiments and process data modelling over the course of technological development stages; and continuous improvement tools [5]. Experimental designs in pharmaceutical industry have improved processes and product performance by selecting the best values for critical parameters in experimental space according to the number of experiments and using the model selected to obtain a satisfactory level of prediction accuracy for its associated response or output (process and product quality attributes) [6].

An experimental approach that can be used for this purpose is uniform experimental design (UD), which is a statistical method involving a significant reduction of the number of experimental runs, mainly applied to experimental regions that have several factors and multiple levels $[7,8]$. However, a disadvantage is data processing derived from UD, which is made by special computer software, and statistical knowledge is necessary due to the absence of preestablished mathematical models [9]. UD is commonly applied for solving industrial problems and widely used in different fields of engineering, including pharmaceutical, chemical, and biological processes [9-11].

UD also can be combined with other mathematics methods such as artificial neural network (ANN) and genetic algorithm (GA) in order to model and optimize output variables, which define process yield and productivity as well as product quality attributes. 
ANN, based on human neural cell processing, has been used in bioprocess as it is suitable for describing nonlinear correlations. This method can usually describe the biological processes better than linear models as well as their intrinsic complexity and high level of uncertainty $[12,13]$. ANN is a computing system comprising highly interconnected process elements (nodes) known as neurons that map a set of input patterns onto a corresponding set of output patterns. The application of ANN in bioprocessing and chemical engineering has increased significantly since the end of the 1980s. Classification, data filtering, process modeling, optimization, and control are among the most important applications of ANN. ANN computing comprises three main steps, data preparation and selection, topological design of ANN, and selection of the training methods along with synaptic weights and biases [14].

The optimization of ANN parameters can be improved using GA, a stochastic global search algorithm, achieving better performances $[15,16]$. GAs simulate the survival-of-the-fittest principle of nature while searching for an objective function that helps in its natural optimization. GAs use string coding of variables for dividing the search space into discrete ones, which further helps in searching for global optimum in the entire solution space. GAs are used for defining ANN topology, selection of training methods, and weights and biases. In addition they have been widely used for searching an optimal bioprocess critical parameter in order to maximize product quality and process efficiency indexes $[17,18]$, which is sometimes referred to as GA-optimized neural network system (GONNS) [19].

The main purpose of this work was to develop a combined ANN-GA algorithm for determining and optimizing an ANN model, which describes rabies virus production in BHK-21 cells based on empirical data, derived from uniform designs with different numbers of experimental runs.

\section{Material and methods}

\subsection{Cell line and culture medium}

BHK-21 (C-13) cells (Sigma-Aldrich ECACC Cell Lines, Lyon, France) suitable for a single-cell suspension culture were kindly supplied by Ecole Superieure Biotechnologie de Strasbourg (France) through Dr. Renaud Wagner. The culture medium was composed of (in volume) 45.5\% Iscove's modified Dulbecco's medium with glutamine and phenol red, 45.5\% high-glucose Dulbecco's modified Eagle's medium, 5\% heat-inactivated fetal bovine serum, $2 \%$ $(10 \% \mathrm{~m} / \mathrm{v})$ Pluronic F-68 aqueous solution, and $2 \% 4 \mathrm{mM}$ glutamine aqueous solution [20].

\subsection{Cell culture}

About $1 \mathrm{~mL}$ of BHK-21 cells of concentration $2 \times 10^{6}$ cell $/ \mathrm{mL}$ was defrosted and placed in a $75-\mathrm{cm}^{2}$ tissue culture flask vertically positioned with $30 \mathrm{~mL}$ of culture medium for growth. After 4 days, the cell suspension of $0.12 \times 10^{6} \mathrm{cell} / \mathrm{mL}$ concentration was inoculated consecutively in other tissue culture flasks of 25 and $75 \mathrm{~cm}^{2}$ along with the addition of an adequate amount of culture medium in order to reach the final cellular suspensions of 10 and $30 \mathrm{~mL}$, respectively. For conducting viral infection assays, cell populations were grown in 100-mL spinner flasks (Bellco Glass Inc., Vineland, $\mathrm{NJ}$, USA), with a working volume of $50 \mathrm{~mL}$; the stirring speed was maintained at $30 \mathrm{rpm}$ (Sci-Era quad drive stirrer system with a stirrer, Bellco Biotechnology, Vineland, NJ, USA). The spinner flasks with an initial cell concentration of $0.25 \times 10^{6}$ cell $/ \mathrm{mL}$ were previously seeded with cells harvested in $75-\mathrm{cm}^{2}$ tissue culture flask in the exponential phase. All the procedures described in this section were performed in an incubator (Thermoforma 3110, Marietta, $\mathrm{OH}$, USA) at $37^{\circ} \mathrm{C}$ and $5 \%$ of carbon dioxide atmosphere. Cell samples from spinner flask at 24,48 , and $72 \mathrm{~h}$ post inoculation were withdrawn for viral infection experiments; the cell concentrations at each moment were $0.75 \times 10^{6}, 2 \times 10^{6}$, and $4 \times 10^{6} \mathrm{cell} / \mathrm{mL}$, respectively. The cell viability was $100 \%$ at the three sampling moments under consideration [21].

\subsection{Virus strain}

Rabies virus strain (CVS-11, ATCC VR 959) conserved at $-80^{\circ} \mathrm{C}$ was provided by Laboratório Especial de Pesquisa e Desenvolvimento em Imunológicos Veterinários (Instituto Butantan, Brazil). Five virus strain passages in BHK-21 cell line were performed, and the corresponding viral titration value was 3.9 [ $\log _{10}$ (fluorescence focus doses $50 \%$ per $50 \mu \mathrm{L}$ )].

\subsection{Rabies virus titration and production quantification}

Preparation of viral titration samples was performed by clarification of the virus suspension using a Millex-HV 0.45- $\mu \mathrm{m}$ PVDF (polyvinylidene fluoride) membrane (Millipore Corporation, Bedford, USA), and the clarified liquid was kept at $-80^{\circ} \mathrm{C}$ until viral titration.

A modified and validated methodology, originally defined in the previous work, was used for rabies virus titration [22,23]. Briefly, $50 \mu \mathrm{L}$ clarified virus suspension samples were serially diluted and seeded in a 96-well microplate(dilution factor: 10) and $100 \mu \mathrm{L}$ of the cell suspension comprising $3.7 \times 10^{4}$ adherent BHK-21 cells in a proper culture medium was added. Subsequently, the microplate was incubated at $37^{\circ} \mathrm{C}$ and $5 \%$ of carbon dioxide atmosphere for $22 \mathrm{~h}$. Then, the culture medium was discarded, and each well was washed with phosphate buffer saline $(0.13 \mathrm{M} \mathrm{NaCl}, 2 \mathrm{mM}$ $\mathrm{KCl}, 8 \mathrm{mM} \mathrm{Na}_{2} \mathrm{HPO}_{4}$, and $\left.15 \mathrm{mM} \mathrm{KH}_{2} \mathrm{PO}_{4}\right)$. Next, $80 \% \mathrm{v} / \mathrm{v}$ acetone aqueous solution at $-20^{\circ} \mathrm{C}$ was added. Consequently, the microplates were dried at room temperature; the cells were labeled with fluorescein-conjugated rabies antiserum (Bio-Rad, Marnes la Coquette, France-cat. \# 72114) for an hour at $37^{\circ} \mathrm{C}$, and washed thrice with phosphate buffer saline. Accordingly, $70 \mu \mathrm{L}$ buffered glycerin ( $\mathrm{pH} 8.5$ ) was added in each well. The microplates were read on an inverted fluorescence microscope $(100 \times$ magnification $)$. Each well was divided into 10 fields, and the fields were considered to be positive if at least one fluorescent focus was observed. The number of positive fields with respect to the total field for each sample dilution was recorded. The viral titration value was calculated as the common logarithm of the reciprocal value corresponding to the highest dilution able to show fluorescent focus in half of the observed fields [ $\log _{10}$ (fluorescence focus doses $50 \%$ per $50 \mu \mathrm{L}$ )]. The software used for viral titration calculations was CombiStats v.4.0 (EDQM-Council of Europe).

The rabies virus production (VP) was calculated as follows (Eqs. (1) and (2)):

$\mathrm{VP}=\log _{10}\left[10^{T}-10^{T_{i}}\right]$, if $T>T_{i}$

$\mathrm{VP}=-\log _{10}\left[10^{T_{i}}-10^{T}\right]$, if $T<T_{i}$

where $T$ and $T_{i}$ are the viral titration values at the defined and initial time, respectively.

\subsection{Experimental designs}

A multilevel factorial design was performed in order to model and optimize rabies virus production. The variables and levels considered were temperature ( 34 and $37^{\circ} \mathrm{C}$ ), time of infection (24, 48 , and $72 \mathrm{~h}$ ), multiplicity of infection $(0.04,0.07$, and 0.1$)$, and virus harvest time $(24,48$, and $72 \mathrm{~h})$. All experimental combinations (54) were performed in triplicate. For each experimental combination, a constant harvest time was set, and the control 


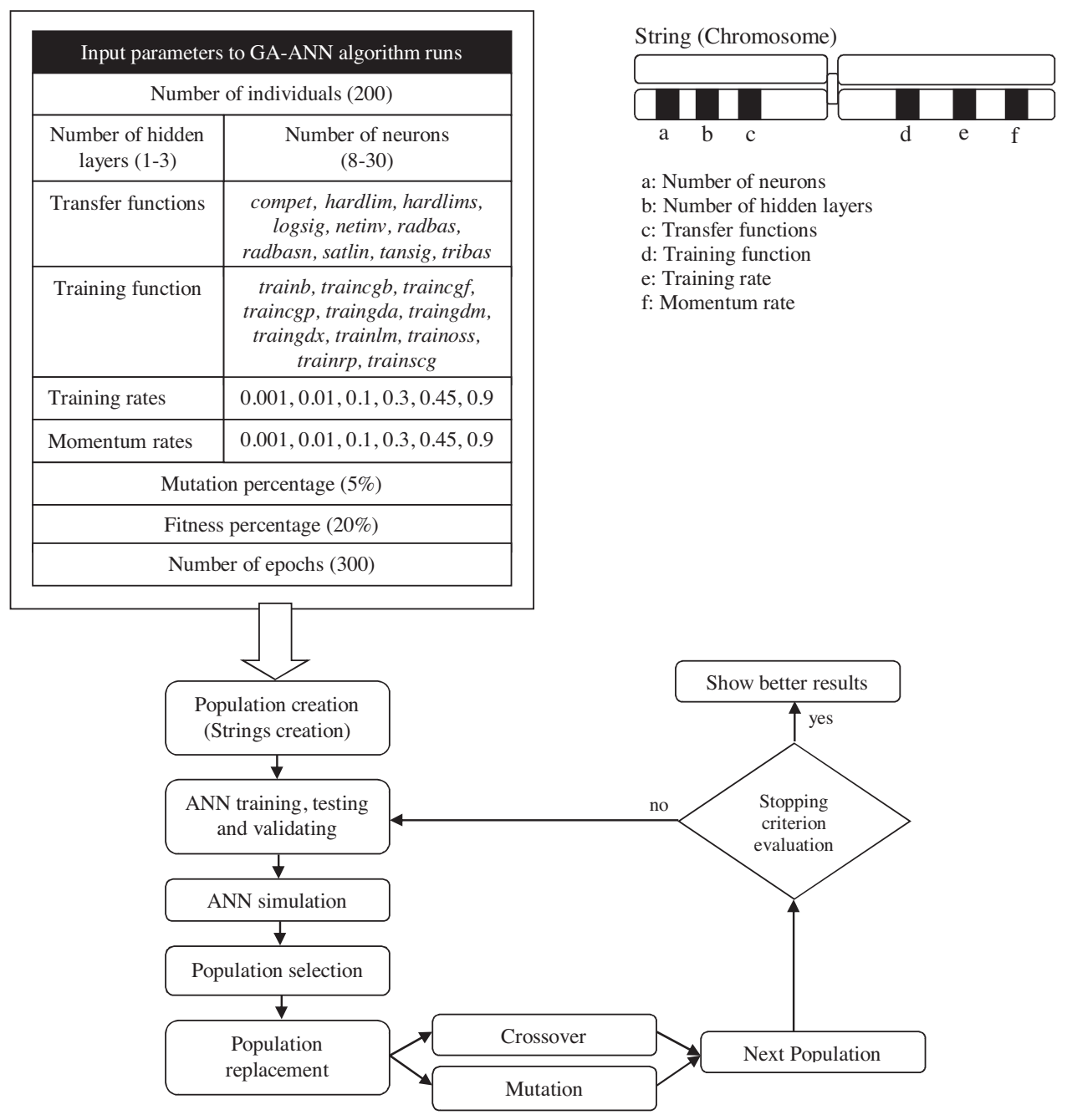

Fig. 1. Flowchart of GA combined with ANN software algorithm for ANN optimization.

assays were performed with BHK-21 cell suspension without the addition of rabies virus.

Five fractions of the combinations associated with the multilevel factorial design performed for modeling rabies virus production were selected. The number of experimental runs $(18,24,30,36$, and 42) of each chosen fraction were defined according to uniform designs based on centered $\mathrm{L}_{2}$-discrepancy (http://sites.stat. psu.edu/ rli/DMCE/UniformDesign/) [24,25].

Pseudo-level techniques were employed for using the uniform design tables previously reported in the literature, which are usually defined for variables with the same number of levels [26]. The experimental matrixes for the five fractions were defined as $U_{n}$ $\left(6^{4}\right)$, where $n, 6$, and 4 represent the number of experimental runs, level number, number of variables, respectively. This step has been previously described [17].

\subsection{Viral infection procedure}

Cell populations grown in $100-\mathrm{mL}$ spinner flask cultures were removed at different post-inoculation times, all included in the growth phase of the cell growth curve. These BHK-21 cell samples were transferred to 12 -well plates (Jet Biofil ${ }^{\circledR}$, Guangzhou, China) and infected with a rabies virus suspension of an adequate volume. During the infection process, the plates were continuously agitated at $100 \mathrm{rpm}$ using digital microtiter shaker (IKA MTS 2/4
DS1, Germany), until the cell and viral suspensions reached a final volume of $2 \mathrm{~mL}$.

\subsection{ANNs combined with GA for virus production modeling}

A homemade GA combined with ANN software was developed in MATLAB platform (MATLAB R2012a, Mathworks Inc., Natick, USA). The steps of GA are described in a flowchart (Fig. 1). The run parameters such as number of individuals, minimum and maximum number of neurons in each hidden layer, number of hidden layers, transfer functions, training functions, training rates, momentum rates, mutation percentage, threshold percentage, and number of epochs were given in the beginning of the software run. First, the population individuals were created by random selection of the string parameters. Individuals represent the ANN parameters, and the strings contain the ANN architectural parameters under consideration. Population selection was based on an elitist strategy, in which the individuals were aligned by testing ANN errors increasingly, using the fitness percentage to maintain the best individuals in the next population. The nonselected individuals were replaced by a crossover strategy, in which its string parameters changed based on a pair of strings randomly picked within the selected individuals. Moreover, this replacement can occur by mutation, depending on the mutation percentage, in which one string parameter can be randomly picked and changed. When the next population was established, the software starts another epoch 
Hidden Layers (1-3)

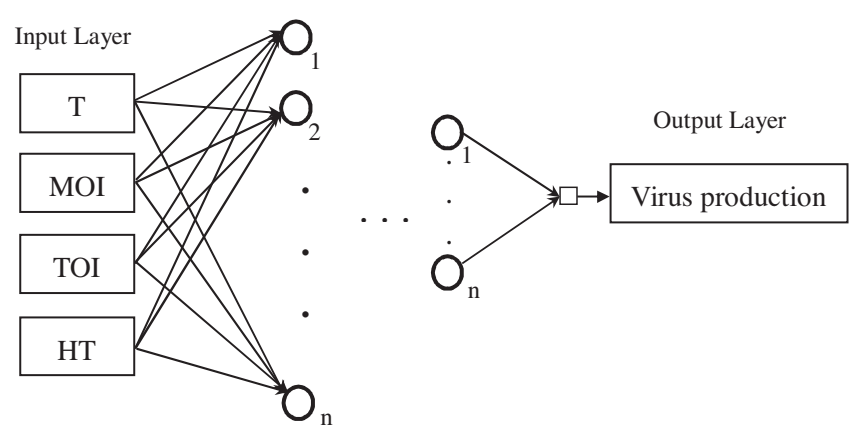

Fig. 2. ANN architecture and input/output pathway.

using this new population. Population selection and replacement continued until a particular number of epochs was achieved [27].

ANNs were trained and tested with the empirical data from multilevel factorial design using a mean squared error (MSE) as the performance index before population selection in each epoch. The temperature, time of infection, multiplicity of infection, and virus harvest time represented the input data, while virus production was the output data. The ANN architecture is described in Fig. 2. Data were randomly divided into training, validation, and testing sets, containing $70 \%, 15 \%$, and $15 \%$, respectively, of the whole data. After training, sets of experimental runs according to uniform designs $(18,24,30,36$, and 42$)$ were simulated by ANN [18,27].

\subsection{Optimization of operational process parameters by GONNS}

The process variables, in multilevel factorial or uniform designs combined with ANN approach, were optimized through GA technique (Optimization Tool, MATLAB R2012a, Mathworks Inc., Natick, USA). The objective function of the latter experimental methodology was the prediction of virus production values for fitted ANN (net) multiplied by-1 (Eqs. (3) and (4)), and the ranges of factor levels were defined in correspondence to the factor ranges in the experimental design. The necessity of multiplication by- 1 was due to GA methodology in MATLAB which is defined for minimization:

$\mathrm{VP}=-\operatorname{sim}[$ net, var]

$\operatorname{var}=\left[\begin{array}{ll}\mathrm{T} & \text { MOI TOI HT }\end{array}\right]$

where var: generic vector comprising input variables, which represent individuals for GA. $T$ : temperature $\left({ }^{\circ} \mathrm{C}\right)$. MOI: multiplicity of infection. TOI: time of infection (h). HT: harvest time (h).

\subsection{Statistical analyses and graphical data treatment}

The conversion of codified values from the uniform design tables into actual values of the factors and graphical data treatment were performed in Excel 2013 (Microsoft Corporation, Redmond, WA, USA). The strength of linear relationships between actual and predicted values of different models was assessed using linear correlation coefficient $(R)[28]$.

\section{Results and discussion}

Manufacturing of viral vaccine is expensive and a complex bioprocess to be optimized [29]. Viral vaccine production is one of the most challenging biopharmaceutical processes, as animal cells should survive in an aggressive biological environment in order to power the viral multiplication [17]. The corresponding biological processes depend on a number of critical parameters. Temperature, time of infection, multiplicity of infection, and harvest time are among the most important factors [30,31]. Beyond the economic and technical problems associated with the development of viral vaccine, the biological risks caused by handling large quantities of infectious material should not be disregarded. Mathematical models to describe virus production are still few. Empirical models are still used for this purpose. The present study was conducted for diminishing experimental works and facilitating derived data analysis in viral vaccine development for other equivalent bioprocesses in future using a standardized ANN model suitable for uniform designs irrespective of the number of experimental runs. In other words, this combined method (uniform design-optimized ANN model) allows less experimental studies and without significant loss of accuracy of the response variable, it reduces costs and data analysis time as well as ensures success in the development process [32,33].

The uniform design approach is of great interest in bioprocesses due to reduction of the number of experiments. This empirical approach decreases experimental time and allows evaluation of several variables and their interactions. Thus, combining this methodology with nonlinear modeling techniques such as ANN improves the model accuracy. In general, the trial-and-error approach is used for defining an ANN model (topology and training methods along with synaptic weights and biases) in order to model virus production process, when uniform designs are chosen [17]. The use of methodology described in the present work would avoid this inefficient procedure, and studies related to this bioprocess could employ this ready modeling tool for efficient application of uniform designs.

Firstly, an ANN model was defined using, as input data, the experimental runs associated with multilevel experimental design. The ANN topology and selection of the training methods along with synaptic weights and biases optimized by ANN-GA algorithm for prediction of virus production from experimental dataset associated with a multilevel factorial design (54 runs) showed a suitable fit to actual values, in concordance with the correlation coefficient values, with the testing, validating, and training correlation coefficients being $0.9948,0.9856$, and 0.9916 , respectively. The parameters of the optimal ANN model are illustrated in Table 1; the MSE evolution for three stages over the course of ANN optimization process is represented in Fig. 3. The average and standard deviation associated with the coefficient of variation for virus production in each experimental combination included in multilevel factorial design was $10.9 \pm 17.0 \%$ (data no shown). Predicted values of virus production from 24 to $72 \mathrm{~h}$ of harvest time were similar to the corresponding observed values at 24,48 , and $72 \mathrm{~h}$ (Fig. 4).

The experimental combinations included in uniform designs from 18 to 42 runs were simulated by the optimal ANN model described earlier, and their correlation coefficients between

Table 1

Description of the ANN architectural parameters optimized by GA-ANN software to predict viral production

\begin{tabular}{|c|c|c|c|c|}
\hline Layer & Numbers of neurons & Transfer functions & Training functions in network & Test error \\
\hline Input & 4 & & Resilient backpropagation algorithm & 0.0052 \\
\hline First hidden & 40 & Positive saturating linear (satlin) & (trainrp) & \\
\hline Second hidden & 53 & Radial basis normalized (radbasn) & & \\
\hline Output & 1 & Hyperbolic tangent sigmoid (tansig) & & \\
\hline
\end{tabular}




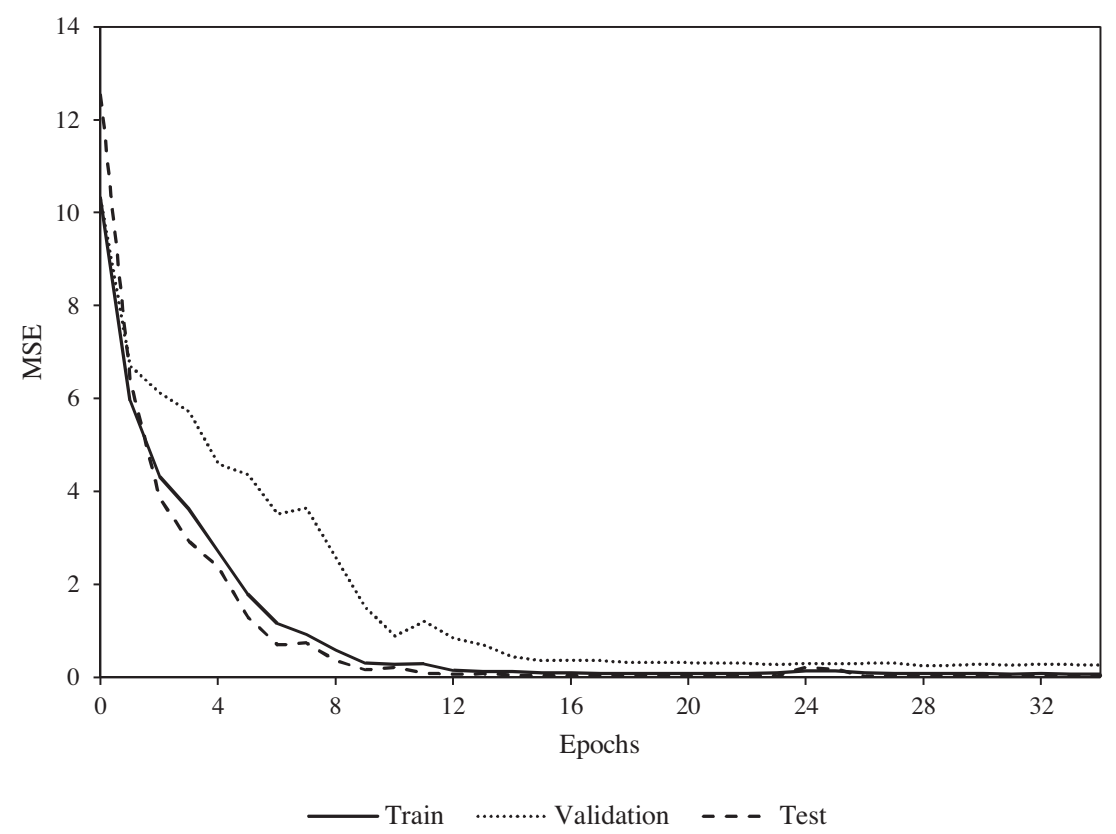

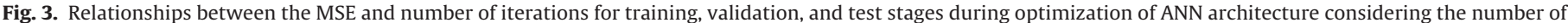
samples included in multilevel factorial designs.

predicted and observed values as well as the corresponding MSEs are defined in Fig. 5. The correlation coefficients were $>0.85$ and MSE was $<1.85$ in all cases. The relative worst prediction results were observed for the UD with the lowest number of runs $\left(18, \mathrm{U}_{18}\right.$ $\left(6^{4}\right)$ ). The equilibrium between accuracy for response variable prediction and experimentation economy was disfavored sharply at $U_{18}\left(6^{4}\right)$ with respect to other uniform designs under consideration. Based on this finding, the use of uniform designs with at least 24 runs could be recommended for viral vaccine processes.

In general, the ANN model optimized by the ANN-GA algorithm evidenced an acceptable calibration for all experimental uniform designs under consideration $(R>0.85$, Fig. 5$)$. The ANN architecture is a major concern with regard to data processing. To date, studies have shown improvement in architectures with multiple layers containing connections between each other with few neurons [34]. The architecture of the two hidden layers optimized by the software (Table 1) contained more neurons compared to that reported previously [17]; in the present work, an increase in the number of neurons improved the accuracy of virus production prediction.

When simulating the optimized ANN for virus production parameters, as shown in Fig. 4, the data generated could be useful for describing the kinetic behavior of this process in the entire experimental domain under study. For experiments performed at both temperatures (Fig. 4), the virus production profile was modified by the time multiplicity of infection. Specifically, for the experiments performed at $34^{\circ} \mathrm{C}$ for a time of infection of $24 \mathrm{~h}$ (Fig. 4A), a decrease in virus production was confirmed at $24 \mathrm{~h}$ post infection; subsequently, a peak of virus production was observed at $48 \mathrm{~h}$. In general, a decrease in extracellular virus concentration at the end of monitoring $(72 \mathrm{~h})$ was found. This is a classical kinetic profile for a lytic, extracellular, labile virus, which explains virus disappearance ("eclipse" phase) immediately after virus inoculation in most of the assessed temperatures and time of infection, during virus attachment and cell penetration. Then, viral titration raised as replicative cycle is completed. Finally, the virus concentration decreases as production terminates, and the newly synthesized virus decays under culture conditions [35]. The time of infection modified this generic profile, wherein a reduction in the harvest time associated with maximum virus production was observed
(Fig. 4A-C). For a time of infection of $72 \mathrm{~h}$, no virus production was detected; this finding could be justified by the nutrient limitations in the culture medium (end of growth phase) [21] and relative low temperature for this cell line $\left(<37^{\circ} \mathrm{C}\right)$, which hinder virus attachment and replication. The highest multiplicity of infection $(0.1)$ led to the highest virus production values at $34{ }^{\circ} \mathrm{C}$ in all the assessed conditions.

The experiments performed at $37^{\circ} \mathrm{C}$ showed worst virus production results for a time of infection of $24 \mathrm{~h}$ (Fig. 4D). The maximum peak of virus production for 0.1 multiplicity of infection was defined at $24 \mathrm{~h}$ post infection for time of infection equal to 48 and $72 \mathrm{~h}$. However, the harvest time associated with maximum virus production was modified for 0.04 and 0.07 multiplicity of infection (Fig. 4E). This could be explained by the influence of virus concentration on virus attachment rate. This fact was not observed probably at time of infection of $72 \mathrm{~h}$ because of the harvest time spacing. The similar values of the maximum virus production for time of infection of 48 and $72 \mathrm{~h}$ could be justified by the combination of virus attachment, penetration, and replication kinetics and mass balance of nutrients in virus-cell systems [31].

Besides, it was possible to define critical parameter values, which maximize virus production, by GONNS. The optimal factor combination described in this method for multilevel factorial design was $36.14{ }^{\circ} \mathrm{C}$ temperature, time of infection of $50.09 \mathrm{~h}, 0.08$ multiplicity of infection, and 24.01-h harvest time, with the optimal virus production being 3.17. This solution is close to the value previously reported (3.28) [17] and the average maximum of observed experimental value was 3.25 (Fig. 4); this shows that the universal ANN optimized by GA approach has promising applications in the development and optimization of bioprocess for viral vaccine production, specifically for rabies vaccines.

\section{Conclusions}

The use of the GA approach for defining a universal architecture (two hidden layers, with 40 and 53 neurons in the first and second hidden layers, respectively) as well as the corresponding transfer functions for neurons and training functions in a network for optimizing an ANN to model rabies virus production was successful. The 

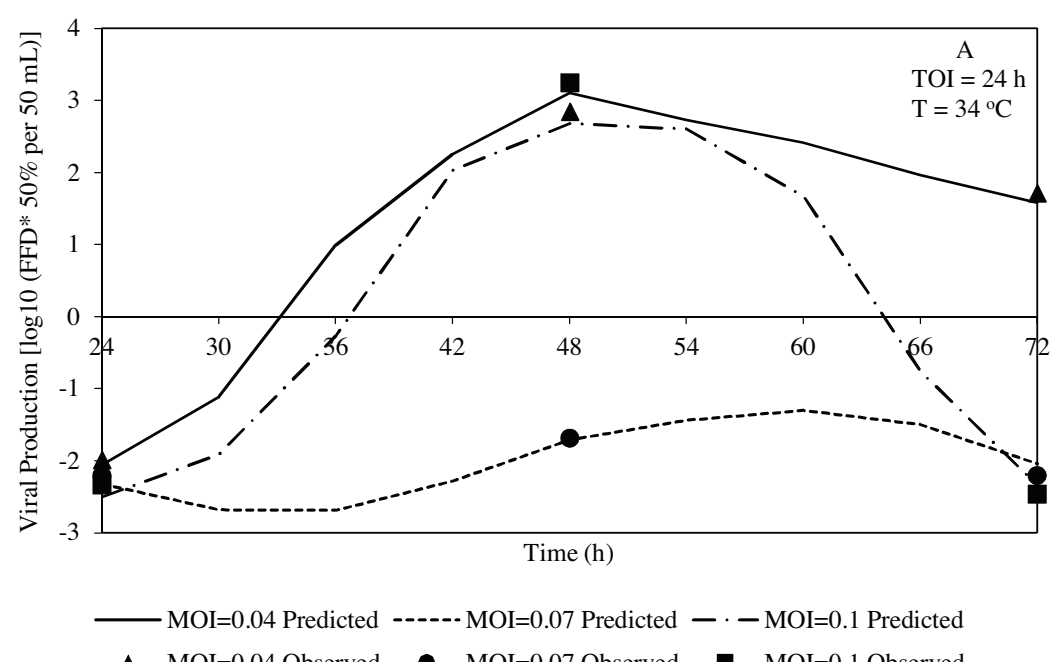

\ $\mathrm{MOI}=0.04$ Observed $-\mathrm{MOI}=0.07$ Observed MOI=0.1 Observed

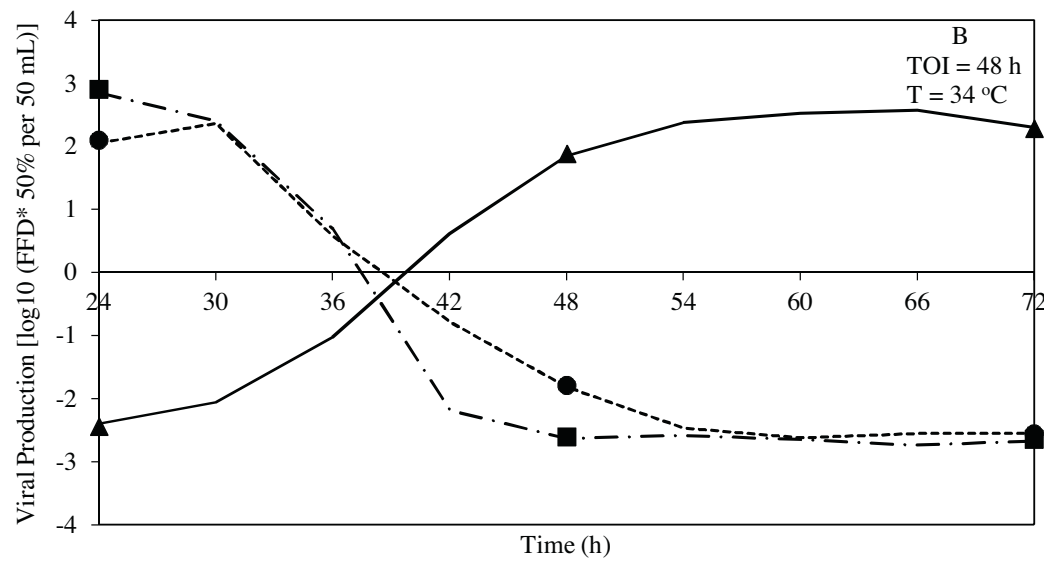

MOI=0.04 Predicted ----- MOI=0.07 Predicted $-\cdots-$ MOI=0.1 Predicted

$\Delta \mathrm{MOI}=0.04$ Observed $\bullet \mathrm{MOI}=0.07$ Observed $\square \mathrm{MOI}=0.1$ Observed

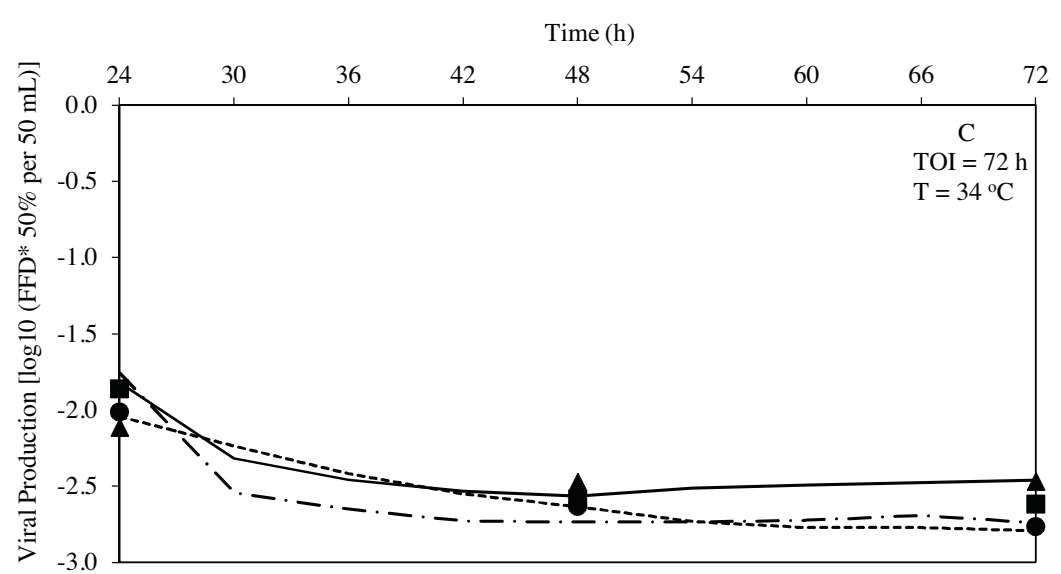

$-\mathrm{MOI}=0.04$ Predicted $-\cdots \cdot-\cdot \mathrm{MOI}=0.07$ Predicted $-\cdots \mathrm{MOI}=0.1$ Predicted

\ MOI=0.04 Observed - MOI=0.07 Observed — MOI=0.1 Observed

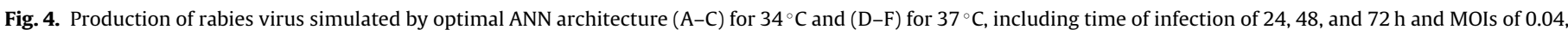

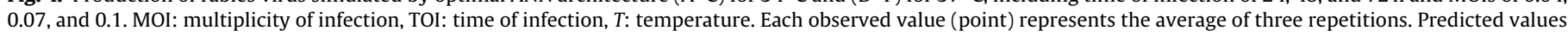
were estimated at every $6 \mathrm{~h}$. 

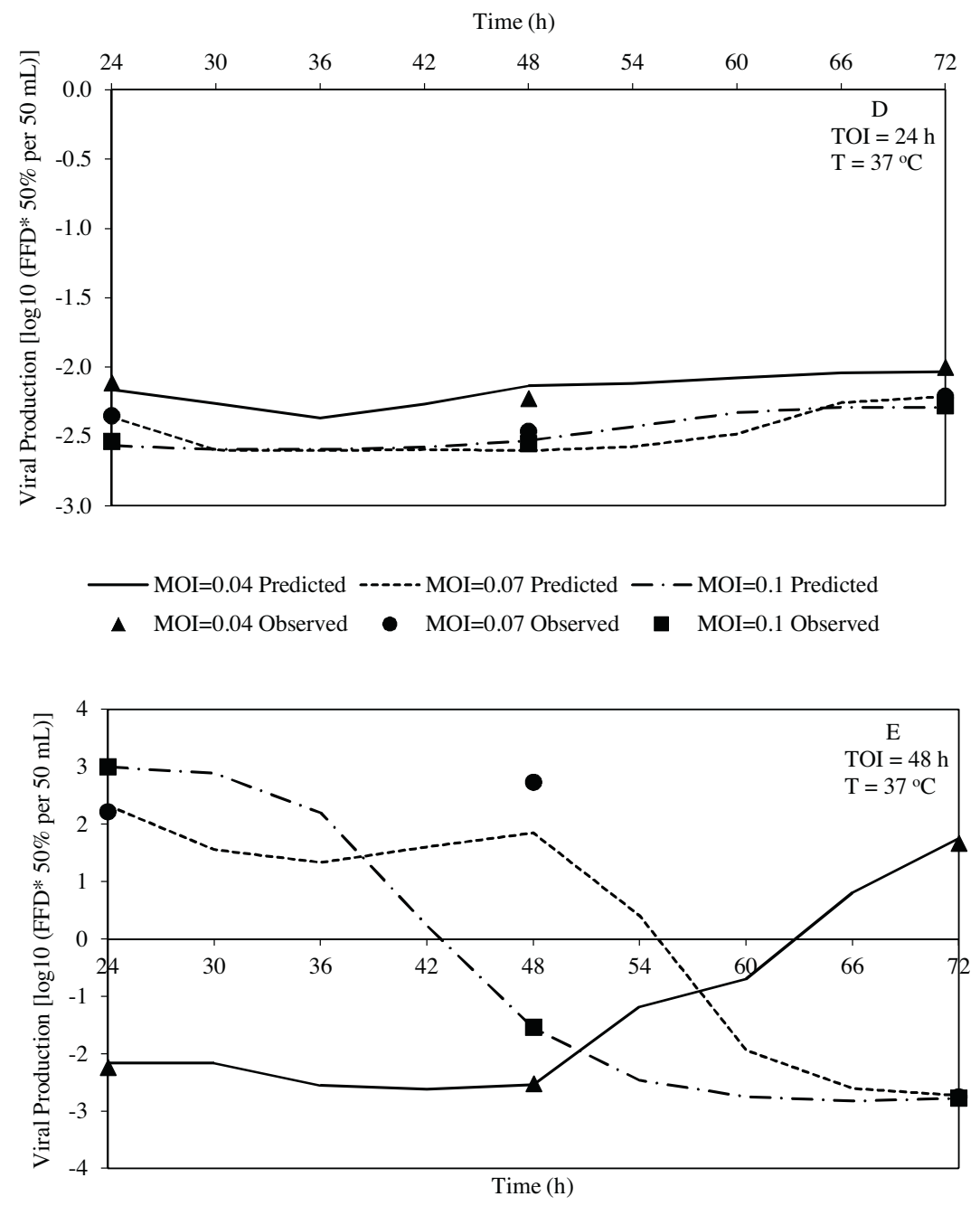

- MOI=0.04 Predicted - - - - MOI=0.07 Predicted $-\cdots-$ MOI=0.1 Predicted

\ $\mathrm{MOI}=0.04$ Observed $\quad \mathrm{MOI}=0.07$ Observed

- $\mathrm{MOI}=0.1$ Observed

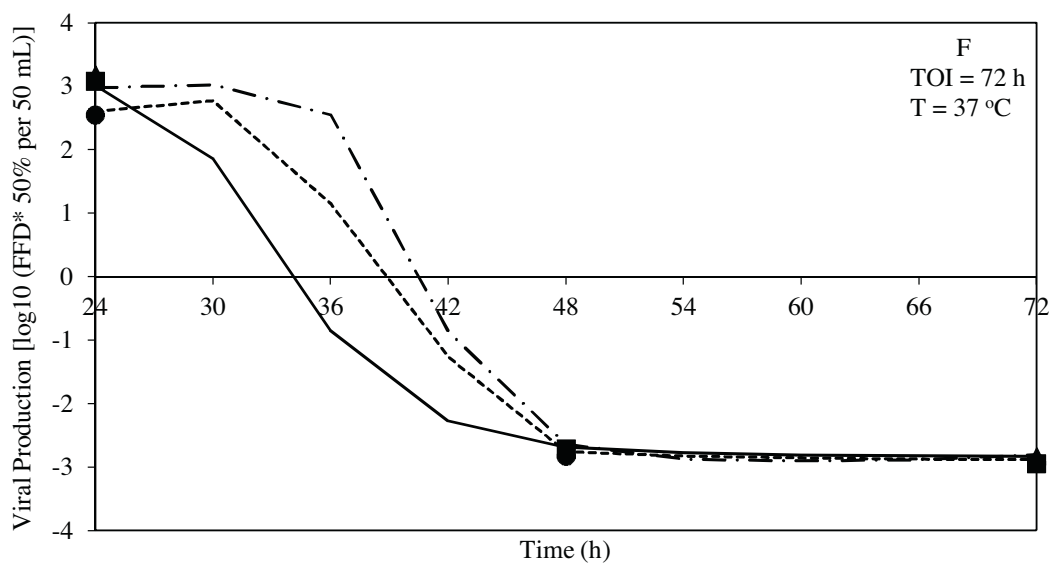

$-\mathrm{MOI}=0.04$ Predicted $-\cdots \cdot-\cdot \mathrm{MOI}=0.07$ Predicted $-\cdots$ MOI $=0.1$ Predicted

\ $\mathrm{MOI}=0.04$ Observed $-\mathrm{MOI}=0.07$ Observed $\square \mathrm{MOI}=0.1$ Observed

Fig. 4. (Continued).

ANN was established using data associated with multilevel experimental design; the optimized ANN model also demonstrated to be suitable as a correlation method in uniform designs (less number of runs) irrespective of the experimental runs that can be conducted, which are defined by cost and time constraints. This finding could guide researchers in the efficient use of a UD as well as in the 


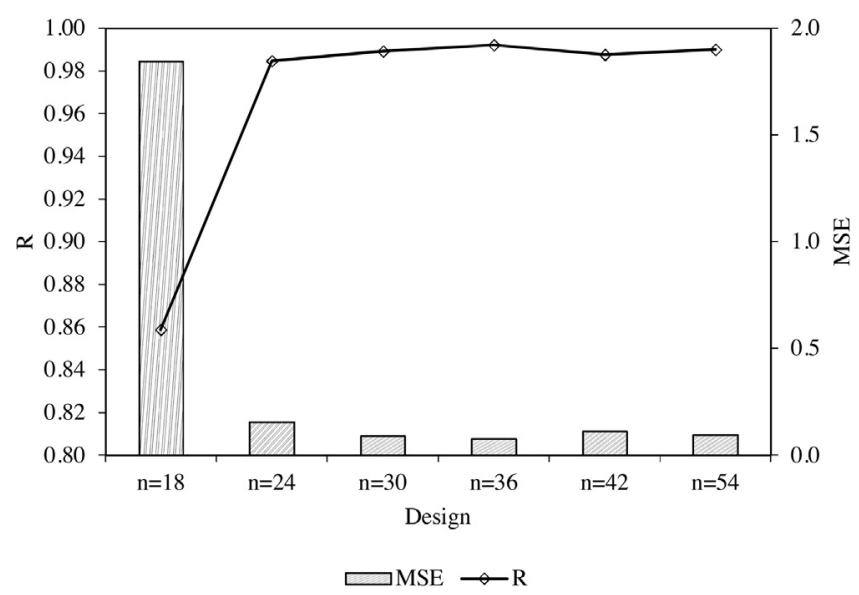

Fig. 5. $R$ and mean squared error (MSE) values from the optimal ANN architecture simulation with experimental data from uniform designs with different number of experimental runs.

analysis, simulation, and optimization of virus production processes. Specifically, for the virus production systems under study, once an ANN model for virus production was defined, the optimal infection conditions $\left(36.14{ }^{\circ} \mathrm{C}\right.$ temperature, $50.09 \mathrm{~h}$ time of infection, 0.08 multiplicity of infection, and 24.01-h harvest time) for maximizing virus production were determined by the GONNS. The bases of methodology presented in this work could be extended to other viral vaccine bioprocess allowing to model them at a low cost and to accelerate their corresponding scale-up process.

\section{Acknowledgments}

The authors would like to thank Fundacão de Amparo à Pesquisa do Estado de São Paulo (FAPESP) for post-doctoral fellowship (2010/52521-6). Authors are also grateful to the staff of Universidade de São Paulo (Laboratório de Células Animais, Escola Politécnica, Brazil) and Instituto Butantan (Laboratório de Imunologia Viral, Laboratório Especial em Pesquisa e Desenvolvimento em Imunológicos Veterinários, Brazil) for their significant collaboration and technical support to acquire the experimental data used in this work.

\section{References}

[1] S. Pichon, F. Guinet-Morlot, M. Minutello, Y. Donazzolo, R. Rouzier, D. Chassard, et al., A serum-free, purified vero cell rabies vaccine is safe and as immunogenic as the reference vaccine Verorab ${ }^{\mathrm{TM}}$ for pre-exposure use in healthy adults: results from a randomized controlled phase-II trial, Vaccine 31 (2013) 2295-2301, http://dx.doi.org/10.1016/j.vaccine.2013.02.058.

[2] S. Rourou, Y. Ben Ayed, K. Trabelsi, S. Majoul, H. Kallel, An animal component free medium that promotes the growth of various animal cell lines for the production of viral vaccines, Vaccine 32 (2014) 2767-2769, http://dx.doi.org/ 10.1016/j.vaccine.2014.02.040.

[3] Who, Weekly epidemiological record Relevé épidémiologique hebdomadaire World Health Organ. Tech. Rep. Ser. 85 (2010) 309-320.

[4] B.S. Riley, X. Li, Quality by design and process analytical technology for sterile products-where are we now? AAPS PharmSciTech 12 (2011) 114-118, http:// dx.doi.org/10.1208/s12249-010-9566-x.

[5] V. Lourenço, D. Lochmann, G. Reich, J.C. Menezes, T. Herdling, J. Schewitz, A quality by design study applied to an industrial pharmaceutical fluid bed granulation, Eur. J. Pharm. Biopharm. 81 (2012) 438-447, http://dx.doi.org/10. 1016/j.ejpb.2012.03.003.

[6] N. Kettaneh-Wold, Use of experimental design in the pharmaceutical industry, J. Pharm. Biomed. Anal. 9 (1991) 605-610, http://dx.doi.org/10. 1016/0731-7085(91)80185-c.

[7] P. He, L. Geng, Z. Wang, D. Mao, J. Wang, C. Xu, Fermentation optimization, characterization and bioactivity of exopolysaccharides from Funalia trogii, Carbohydr. Polym. 89 (2012) 17-23, http://dx.doi.org/10.1016/j.carbpol.2012. 01.093.

[8] R.S. Liu, Y.J. Tang, Quantitative analysis for the effect of plant oil and fatty acid on Tuber melanosporum culture by uniform design combined with partial least squares regression, Appl. Microbiol. Biotechnol. 87 (2010) 1689-1697, http://dx.doi.org/10.1007/s00253-010-2602-7.

[9] T. Chun-Hong, W. Bo-Chu, C. Qi, Z. Li, C. Shao-Xi, A new experimental design for screening Chinese medicine formula, Colloids Surf. B Biointerfaces 36 (2004) 105-109, http://dx.doi.org/10.1016/j.colsurfb.2004.05.013.

[10] T. Zhang, X.G. Chen, Application of uniform design genetic algorithm in separation condition optimization of 14 Drugs, Adv. Eng. Res. (2015) 550-552.

[11] W. Peng, J. Zhong, J. Yang, Y. Ren, T. Xu, S. Xiao, et al., The artificial neural network approach based on uniform design to optimize the fed-batch fermentation condition: application to the production of iturin A, Microb. Cell Fact. 13 (2014) 54, http://dx.doi.org/10.1186/1475-2859-13-54.

[12] S. Vats, S. Negi, Use of artificial neural network (ANN) for the development of bioprocess using Pinus roxburghii fallen foliages for the release of polyphenols and reducing sugars, Bioresour. Technol. 140 (2013) 392-398, http://dx.doi. org/10.1016/j.biortech.2013.04.106.

[13] M.B. Takahashi, J. Leme, C.P. Caricati, A. Tonso, E.G. Fernández Núñez, J.C. Rocha, Artificial neural network associated to UV/vis spectroscopy for monitoring bioreactions in biopharmaceutical processes, Bioprocess Biosyst. Eng. 38 (2015) 1045-1054, http://dx.doi.org/10.1007/s00449-014-1346-7.

[14] D.R. Baughman, Y.A. Liu, Neural Networks in Bioprocessing and Chemical Engineering, Elsevier, 1995, http://dx.doi.org/10.1016/B978-0-12-083030-5. 50007-2.

[15] J. Peng, F. Meng, Y. Ai, Time-dependent fermentation control strategies for enhancing synthesis of marine bacteriocin 1701 using artificial neural network and genetic algorithm, Bioresour. Technol. 138 (2013) 345-352, http://dx.doi.org/10.1016/j.biortech.2013.03.194.

[16] B. Gurunathan, R. Sahadevan, Design of experiments and artificial neural network linked genetic algorithm for modeling and optimization of L-asparaginase production by Aspergillus terreus MTCC 1782, Biotechnol. Bioprocess Eng. 16 (2011) 50-58, http://dx.doi.org/10.1007/s12257-0100119-7.

[17] L.H. Buenno, J.C. Rocha, J. Leme, C.P. Caricati, A. Tonso, E.G. Fernández Núñez Use of uniform designs in combination with neural networks for viral infection process development, Biotechnol. Prog. 31 (2015) 532-540, http:// dx.doi.org/10.1002/btpr.2051.

[18] G. Dhanarajan, M. Mandal, R. Sen, A combined artificial neural network modeling-particle swarm optimization strategy for improved production of marine bacterial lipopeptide from food waste, Biochem. Eng. J. 84 (2014) 59-65, http://dx.doi.org/10.1016/j.bej.2014.01.002.

[19] S. Elhami, M.R. Razfar, M. Farahnakian, A. Rasti, Application of GONNS to predict constrained optimum surface roughness in face milling of high-silicon austenitic stainless steel, Int. J. Adv. Manuf. Technol. 66 (2012) 975-986, http://dx.doi.org/10.1007/s00170-012-4382-y.

[20] J. Leme, E.G. Fernández Núñez, L. de Almeida Parizotto, W.A. Chagas, E.S. dos Santos, A.T.P. Caricati, et al., A multivariate calibration procedure for UV/VIS spectrometric monitoring of BHK-21 cell metabolism and growth, Biotechnol. Prog. 30 (2014) 241-248, http://dx.doi.org/10.1002/btpr.1847.

[21] E.G. Fernández Núñez, J. Leme, L. de Almeida Parizotto, A.G. de Rezende, B.L.V. da Costa, V.L.L. Boldorini, et al., Approach toward an efficient inoculum preparation stage for suspension BHK-21 cell culture, Cytotechnology. doi (2014), http://dx.doi.org/10.1007/s10616-014-9756-6.

[22] R.M.M. Fuches, Ph.D. Thesis, Universidade de São Paulo, São Paulo, Brazil, 2010

[23] P. Perrin, S. Madhusudana, C. Gontier-Jallet, S. Petres, N. Tordo, O.W. Merten, An experimental rabies vaccine produced with a new BHK-21 suspension cell culture process: use of serum-free medium and perfusion-reactor system, Vaccine 13 (1995) 1244-1250.

[24] K.-T. Fang, D.K.J. Lin, Statistics in Industry, Elsevier, 2003, http://dx.doi.org/10. 1016/S0169-7161(03)22006-X.

[25] K.-T. Fang, D.K.J. Lin, P. Winker, Y. Zhang, Uniform design: theory and application, Technometrics 42 (2000) 237-248, http://dx.doi.org/10.1080/ 00401706.2000.1048604.

[26] L.D.K. Fang, Uniform experimental design and their applications in industry, in: R. Khattree, C. Rao (Eds.), Handb. Stat. 22 Stat. Ind., Elsevier Science B.V., Amsterdam, 2003, pp. 131-170.

[27] A.P. Alves, Tutorial genetic algorithms, Rev. Da Soc. Bras. Redes Neurais. 1 (2003) 38-48

[28] D. Güçlü, S. Dursun, Artificial neural network modelling of a large-scale wastewater treatment plant operation, Bioprocess Biosyst. Eng. 33 (2010) $1051-1058$.

[29] T. Vicente, A. Roldão, C. Peixoto, M.J.T. Carrondo, P.M. Alves, Large-scale production and purification of VLP-based vaccines, J. Invertebr. Pathol. 107 (Suppl) (2011) S42-S48, http://dx.doi.org/10.1016/j.jip.2011.05.004.

[30] S. Jung, L.A. Behie, P.W.K. Lee, P.J. Farrell, Optimization of reovirus production from mouse L-929 cells in suspension culture, Biotechnol. Bioeng. 85 (2004) 750-760, http://dx.doi.org/10.1002/bit.20012.

[31] L. Chan, S. Reid, L.K. Nielsen, Baculovirus kinetics, insect culture, in: M. Flickinger (Ed.), Upstream Industrial Biotechnology, 1, John Wiley \& Sons, Inc. Hoboken, NJ, USA, 2013, pp. 33-48.

[32] Z. Wang, D. Luo, C. Ena, Optimization of polysaccharides extraction from Gynostemma pentaphyllum Makino using Uniform Design, Carbohydr. Polym. 69 (2007) 311-317, http://dx.doi.org/10.1016/j.carbpol.2006.10.013.

[33] L. Zhang, Y.-Z. Liang, J.-H. Jiang, R.-Q. Yu, K.-T. Fang, Uniform design applied to nonlinear multivariate calibration by ANN, Anal. Chim. Acta 370 (1998) 65-77, http://dx.doi.org/10.1016/s0003-2670(98) 00256-6. 
[34] H. Hunter, M.S. Yu, J. Pukish, B.M. Kolbusz, Selection of proper neural network sizes and architectures-a comparative study, IEEE Trans. Ind. Inform. 8 (2012) 228-240, http://dx.doi.org/10.1109/TII.2012.2187914.
[35] J. Aunins, Viral vaccine production in cell culture, in: M. Flickinger (Ed.), Encyclopedia of Industrial Biotechnology: Bioprocess, Bioseparation, and Cell Technology, Wiley, NY, 2010, pp. 1-52. 